Brit. J. industr. Med., 1961, 18, 295.

\title{
THE TOXICITY OF PRECIPITATED SILICA
}

\author{
BY \\ P. D. BYERS and J. C. GAGE \\ From the Postgraduate Medical School, Hammersmith and Imperial Chemical \\ Industries Limited, Industrial Hygiene Research Laboratories
}

(RECEIVED FOR PUbliCATION APRIL 4, 1961)

\begin{abstract}
The proportion of respirable particles in dust clouds generated from three samples of precipitated silica has been shown to range between one-quarter and one-third by weight.

After a single intratracheal dose of the silicas to rats, chemical analysis shows a progressive disappearance of silica from the lungs, though it is still detectable after 12 months. Some silica appears in the liver and kidneys but in two of the three samples none remains after 12 months.

The nature and duration of the lung lesions produced in rats after a single intratracheal injection are described. A mild degree of fibrosis was observed which showed a steady regression with time and was to some extent influenced by the nature of the silica injected. The lesions showed little resemblance to those arising from quartz and were more akin to those produced by non-fibrogenic dusts.

Recommendations are made for the precautions to be taken during the industrial handling of these dusts.
\end{abstract}

Amorphous silica has been used for many years in a variety of industries, notably for inclusion into rubber formulations as a filler. Although it appears to have been handled without special precautions, no authenticated case of silicosis or other respiratory disease has been traced which can be attributed to this agent. Nevertheless, the increasing industrial usage of this material has aroused some concern lest hitherto unsuspected toxic properties might emerge.

Amorphous silica is not a clearly defined chemical entity and several methods are employed for its commercial production. Most of the experimental investigations into the toxicity of amorphous silica have been concerned with "flame" silica, prepared by burning a mixture of hydrogen and silicon tetrachloride vapour. It has been shown that this type of silica has a cytotoxic action (Policard and Collet, 1957) and can be lethal when injected intravenously (Swensson, Glomme, and Bloom, 1956), but that when inhaled it produces a reversible lesion in the lungs with only a mild degree of fibrosis and with very little collagen deposition (Schepers, Delahant, Bailey, Gockeler, and Gay, 1957a). Similar effects on the lungs have been shown by intratracheal injections (Klosterkötter and Jötten, 1953).

Another commercially important type of amorphous silica is prepared by acid precipitation from an aqueous solution of sodium silicate, a process similar to that used for the preparation of silica gel. There do not appear to have been any systematic investigations into the toxicity of this precipitated silica, which cannot be assumed to be identical with that of "flame" silica as there is no certainty that the two substances have the same composition. An investigation of precipitated silica from two manufacturers has, therefore, been undertaken, in order to assess the possibility of a silicosis hazard from the industrial use of this material.

Fibrogenic properties of a dust can be determined by studying the cellular reaction to the dust within the lung. Experimentally, dust can be introduced by exposing animals to a dusty atmosphere or injecting dust in some form of suspension directly into the lung. In the former method, the animals automatically select those particles which can enter the respiratory system sufficiently far to be retained (Dautrebande, Beckmann, and Walkenhorst, 1957). In the injection method, the size distribution of the material depends on the degree of dispersion in the suspension administered. Apart from considerations of particle size, the injection method probably provides at least as severe a test of the fibrogenic capacity of a dust as do dusting procedures (Schepers, Durkan, Delahant, Creedon, and Redlin, 1957b; Belt and King, 1945; Kettle and Hilton, 1932). 
Amorphous silicas are composed of very fine particles, the average diameter being in the region of $20 \mathrm{~m} \mu$, which tend to aggregate loosely in air. The size of these aggregates will determine the respirable fraction of the dust, rut will not necessarily determine the effect of the dust once it has entered the body, since the silica may then be exposed to other influences causing a variation in the degree of aggregation.

We have performed two types of experiment with three amorphous silicas. In the first, the proportion of respirable particles in air-borne precipitated silica dust clouds has been measured. In the second we have administered to rats, by intratracheal injection, single doses of the samples, and have studied the distribution and excretion of silica and the nature and duration of the lesions produced.

\section{Samples Investigated}

Samples of precipitated silica were obtained from two manufacturers. From one supplier two samples were received; sample $A 1$, the quality normally supplied, and the sample A2 which had the same characteristics when originally manufactured, but which had for reasons not clearly known increased in particle size on ageing. Sample B was obtained from the second supplier.

Sample A1.-The particle size was $19 \mathrm{~m} \mu$, calculated by an air permeability method (Pechukas and Gage, 1946).

Sample A2.-When freshly prepared this was shown by electron microscopy to have a particle size of $20 \mathrm{~m} \mu$ and a specific surface by gas absorption of $110 \mathrm{~m} .{ }^{2} / \mathrm{g}$. A later measurement of the specific surface showed that this had decreased to $60 \mathrm{m.}^{2} / \mathrm{g}$. and an air permeability measurement gave a particle size of $60 \mathrm{~m} \mu$.

Sample B.-The particle size by an air permeability method was $25 \mathrm{~m} \mu$.

The intravenous toxicity of the three samples has been determined on rats. Most deaths occurred within two hours of injection and all rats surviving for 24 hours subsequently recovered. The following $\mathrm{LD}_{50}$ values were obtained, with the fiducial limits $(p=0.05)$ given in parentheses: sample A1, 35.2 (32-39); sample A2, 41.2 (34.5-42); sample B, 44.4 (40.5-49) mg./kg. These figures are appreciably higher than the values $7-17 \mathrm{mg} . / \mathrm{kg}$. obtained on mice with "flame" silica by Swensson et al. (1956).

\section{The Respirable Fraction of Precipitated Silica}

Theoretical and experimental studies have shown that the ability of dust particles to penetrate into the lungs when inhaled is related to their free falling speed in air and is, therefore, determined by their size and density (Davies, 1952). It is thought that quartz particles with a diameter greater than about $7 \mu$ are trapped in the upper respiratory passages and do not enter the lung alveoli and give rise to silicosis (Wright, 1954). The ultimate particle size of precipitated silica is very much less than this figure, but the particles are associated into loose aggregates whose density will be much lower than that of quartz. The upper size limit for penetration into the lung by these aggregates is uncertain but will be greater than the $7 \mu$ quoted for quartz. A classification of a precipitated silica dust cloud by direct measurement of aggregate size would, therefore, have only a limited value as a guide to the pneumoconiosis hazard from the dust, and it would be preferable to base the size analysis on the free falling speed of the particles. A determination of the aggregate size range by trapping the dust in a liquid followed by elutriation would probably be unsuitable as the forces at the solid-liquid interface might change the degree of dispersion. The instrument selected for studying the precipitated silica dust was the Hexhlet Air Elutriator (Casella Ltd.) which collects the fraction of the dust with a free falling speed in air sufficiently low to permit penetration into the lungs (Wright, 1954).

\section{Apparatus}

The dust cloud was generated by a modification of the United States Bureau of Mines Apparatus (Schrenk, 1939), in which the dust is filled into a long vertical cylindrical container which is slowly raised at a uniform speed to maintain the surface of the dust in contact with a static head. From this head the dust is aspirated into the air stream by means of a Venturi jet. The original apparatus was designed for a much larger scale than was convenient for these experiments and an attempt to reduce it in size was unsatisfactory as an intermittent dust feed was obtained. This difficulty was overcome by applying an oscillatory rotation to the dust container and a positive flow control to the air supply used to pick up the dust from the static head and introduce it into the main air stream. The apparatus used is shown diagrammatically in Fig. 1. The dust container, A, was constructed from a precision $5 \mathrm{~mm}$. bore glass tube, $20 \mathrm{~cm}$. long, surmounted by a B 14 standard taper socket. A side arm, B, was connected through a flow meter to an air line with flow control. A brass piston, C, $12 \mathrm{~mm}$. long and bearing 12 longitudinal flutes, slid easily into the tube A. A thin-walled stainless steel tube, D, $1.5 \mathrm{~mm}$. diameter and $25 \mathrm{~cm}$. long was fixed into a hole bored centrally in the piston. This tube also passed through a hole drilled in a "Perspex" cone, E, fitted in the B 14 socket and forming an air-tight seal but permitting movement of the tube in the cone. The upper end of the tube was clamped and the tip entered a hole in the base of an open-ended "Perspex" box attached to the end of the Hexhlet apparatus.

The dust container was mounted in a bored rubber stopper in an adaptor on the ram, F, of a slow injection apparatus (C. F. Palmer Ltd.) which had been modified by the makers for a vertical drive. This apparatus was capable of raising the dust container a distance of 4 in. at constant rates which could be varied between 1 in. in 10 to 320 minutes. A horizontal slotted bar, G, was also attached to the rotating head of the ram and in the slot was a vertical pin, $\mathbf{H}$, on an adjustable crank which turned by means of a geared down electric motor at a speed of 30 r.p.m. The vertical pin on the crank was sufficiently long to impart an oscillating angular motion of about $65^{\circ}$ to the slotted bar, whatever the position of the ram. 


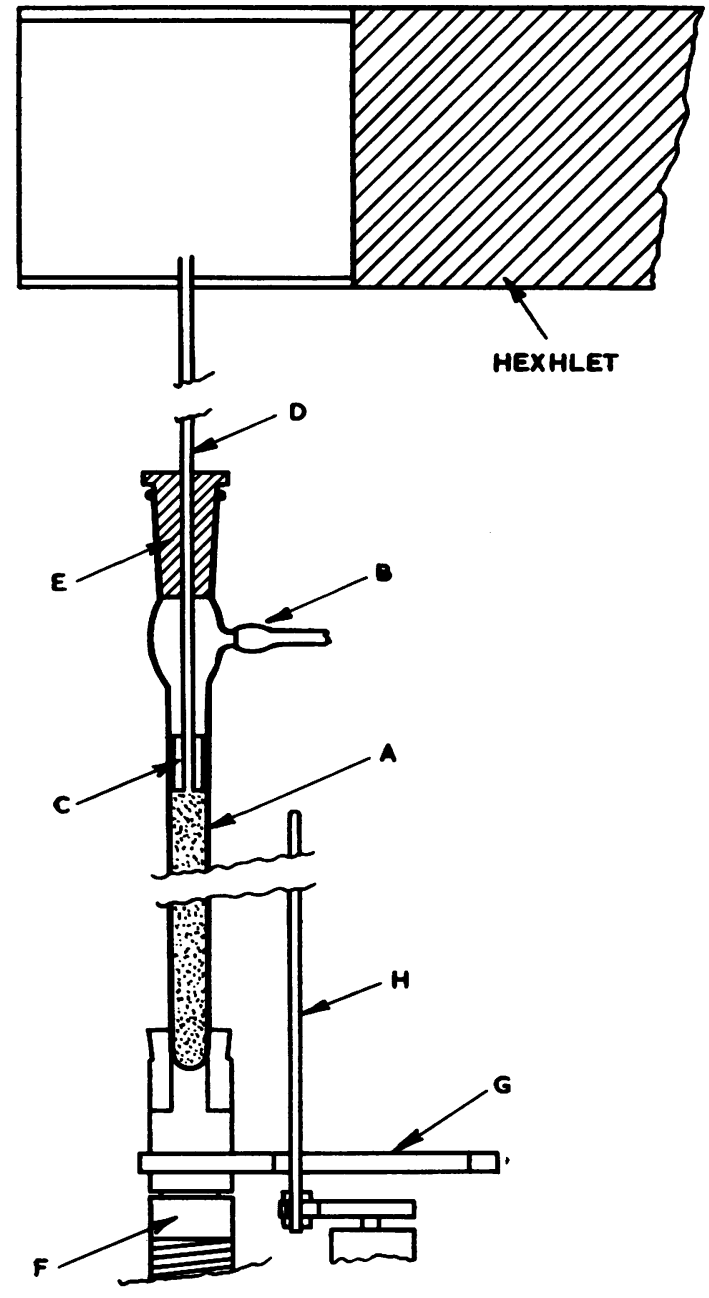

Fig. 1.-Apparatus for the generation of silica dust clouds. A, dust container; B, entry of air for dust pick-up; C, fluted brass piston; D, stainless steel tube; E, "Perspex" cone; F, ram of slow injection apparatus; $G$, slotted bar; $H$, rotating pin.

A weighed amount of the silica sample to be examined was introduced in portions into the dust container, the tube being tapped between each addition. The apparatus was assembled as shown in Fig. 1, and with a soxhlet thimble of known ash weight in the Hexhlet apparatus. The air line to the Hexhlet was turned on, and $0.21 . / \mathrm{min}$. dry air was passed through the side arm of the dust reservoir. The vertical drive on the dust container was started at a speed of 1 in. in $40 \mathrm{~min}$. and the agitator switched on. By this means the dust was caused to issue at a known rate from the tip of the vertical tube and enter the air stream passing at a rate of $1001 . / \mathrm{min}$. into the Hexhlet.
The run on each sample was continued for two to three hours at the end of which the dust remaining in the container was weighed and hence the total injected into the air stream was calculated. The soxhlet thimble was removed and ashed and the residue weighed and corrected for the ash of the thimble and the measured percentage of loss in weight of the silica sample at the ashing temperature. The results of duplicate experiments on the three samples are shown in Table 1.

The figures in the third column of Table 1 show that the respirable fraction of the precipitated silica samples ranged between 25 and $40 \%$. Both samples from manufacturer A showed a smaller proportion of fine particles than the sample B. The apparently greater aggregate size of sample A2 may be related to the statement that this sample had changed in its physical properties on ageing leading to an increase in the ultimate particle size, and also to the observation made in subsequent experiments that this sample is more difficult to disperse in water. The variation in the atmospheric concentration in duplicate experiments shown in Table 1 must be attributed to differences in the degree of packing of the powder in the dust container; nevertheless, the duplicates on the percentage reaching the filter are in tolerably good agreement.

TABLE 1

\section{RESPIRABLE FRACTION OF PRECIPITATED} SILICA DUST

\begin{tabular}{|c|c|c|c|c|c|}
\hline \multirow{2}{*}{ Sample } & \multicolumn{2}{|c|}{ Weight Silica (mg.) } & \multirow{2}{*}{$\begin{array}{l}\% \text { Silica } \\
\text { on Filter }\end{array}$} & \multirow{2}{*}{$\underset{\text { (min.) }}{\text { Duration }}$} & \multirow{2}{*}{$\begin{array}{l}\text { Atmospheric } \\
\text { Concentra- } \\
\text { tion (mg./m. }\end{array}$} \\
\hline & Injected & Collected & & & \\
\hline A1 & $\begin{array}{l}369 \\
285\end{array}$ & $\begin{array}{r}107 \\
96\end{array}$ & $\begin{array}{l}29 \cdot 0 \\
33 \cdot 7\end{array}$ & $\begin{array}{l}130 \\
120\end{array}$ & $\begin{array}{l}28 \cdot 4 \\
23 \cdot 7\end{array}$ \\
\hline $\mathbf{A} 2$ & $\begin{array}{l}603 \\
479\end{array}$ & $\begin{array}{l}148 \\
129\end{array}$ & $\begin{array}{l}24 \cdot 5 \\
27 \cdot 0\end{array}$ & $\begin{array}{l}170 \\
170\end{array}$ & $\begin{array}{l}35 \cdot 5 \\
28 \cdot 2\end{array}$ \\
\hline $\mathbf{B}$ & $\begin{array}{l}457 \\
280\end{array}$ & $\begin{array}{r}198 \\
98\end{array}$ & $\begin{array}{l}43 \cdot 3 \\
35 \cdot 0\end{array}$ & $\begin{array}{l}170 \\
120\end{array}$ & $\begin{array}{l}26 \cdot 9 \\
23 \cdot 3\end{array}$ \\
\hline
\end{tabular}

\section{Retention of Precipitated Silica in I.ungs}

Groups of 50 male and 50 female adult Wistar strain albino rats were injected intratracheally under light ether anaesthesia with $1 \mathrm{ml}$. of a $2.5 \%$ suspension of each of the samples of precipitated silica. The silica was sterilized in hot air at $160^{\circ} \mathrm{C}$. for two hours and dispersed in sterile isotonic saline by means of a Griffith's tube. Higher doses than $25 \mathrm{mg}$./rat caused death within 24 hours. The first injections were made with sample A2 and although initially all rats tolerated the dose well, 12 of the group died within four days with post-mortem signs of consolidation and abscess formation in the lungs. In experiments on the other two samples, which were started several months later, 2,000 units of penicillin were included in the injection and no immediate deaths from lung infection occurred. At three intervals during the 12 months after injection five male and five female rats were killed and the lungs, liver, kidneys, and spleen were taken for silica determinations. Similar groups were killed for a histopathological examination of the lungs. 
Silica was determined in the tissues by a modification of the method of King, Stacy, Holt, Yates, and Pickles (1955). A $50 \%$ aqueous homogenate of each sample was prepared and $2 \mathrm{~g}$. was fused with $2 \mathrm{~g}$. sodium carbonate in a platinum crucible. Heating was gentle during charring of the tissue and was then applied more strongly until the melt remained white on cooling. The melt was dissolved in water by gently warming and was then cautiously neutralized to Congo Red with $10 \mathrm{~N}$ sulphuric acid, and a further $0.2 \mathrm{ml}$. of the acid added. The solution was diluted to $50 \mathrm{ml}$. with water and 1 or $2 \mathrm{ml}$. portions taken for analysis. The subsequent colorimetric determination of silica followed the method described by King et al. (1955), the optical density of the blue colour being measured at $810 \mathrm{~m} \mu$. The results of these analyses, expressed as $\mu \mathrm{g}$. $\mathrm{SiO}_{2}$ per rat, are given in Table 2, together with the average silica content of tissue from normal rats.

TABLE 2

RETENTION OF SILICA BY RAT TISSUES

\begin{tabular}{|c|c|c|c|c|c|}
\hline Sample & $\begin{array}{c}\text { Weeks } \\
\text { After } \\
\text { Injection }\end{array}$ & Lungs & Liver & Kidneys & Spleen \\
\hline A1 & $\begin{array}{l}12 \\
24 \\
52\end{array}$ & $\begin{array}{r}1,570 \\
755 \\
210\end{array}$ & $\begin{array}{r}177 \\
20 \\
61\end{array}$ & $\begin{array}{l}33 \\
12.4 \\
9.7\end{array}$ & $\begin{array}{l}0 \\
1 \cdot 4 \\
0\end{array}$ \\
\hline $\mathbf{A 2}$ & $\begin{array}{l}12 \\
36 \\
52\end{array}$ & $\begin{array}{r}5,150 \\
1,550 \\
720\end{array}$ & $\begin{array}{l}249 \\
153 \\
153\end{array}$ & $\begin{array}{l}138 \\
44 \\
56\end{array}$ & $\begin{array}{r}0 \\
19 \\
0\end{array}$ \\
\hline B & $\begin{array}{l}12 \\
24 \\
52\end{array}$ & $\begin{array}{l}652 \\
324 \\
108\end{array}$ & $\begin{array}{r}234 \\
43 \\
38\end{array}$ & $\begin{array}{l}34 \\
8 \cdot 9 \\
12\end{array}$ & $\begin{array}{l}5.8 \\
1.4 \\
0\end{array}$ \\
\hline \multicolumn{2}{|c|}{$\begin{array}{l}\text { Average silica con- } \\
\text { tent of normal } \\
\text { rat tissue }\end{array}$} & 28 & 37 & 11 & 5 \\
\hline
\end{tabular}

All rats received an intratracheal dose of $25 \mathrm{mg}$. precipitated silica. Figures represent $\mu \mathrm{g}$. $\mathrm{SiO}_{2}$ per rat.

\section{Effect of Precipitated Silica on Lungs}

Groups of five male and five female rats, dosed intratracheally with each of the precipitated silicas as described in a previous section, were taken at three intervals over a period of 12 months for histopathological examination of the lungs. Sections of the whole lungs, cut in the frontal plane, were stained with haematoxylin and eosin, and others impregnated with silver for reticulin fibres. Other sections were micro-incinerated, with and without acid-washing, and a few were stained with Van Giesen.

An examination of the acid-washed incinerated sections showed that the distribution of silica in the lungs was not uniform, but occurred in small areas throughout one or both lungs with occasionally a large amount deposited in one lung segment. The stained sections showed that the three dusts elicited the same type of response in the lungs and that there was no significant difference between the effects produced in male and female rats. The silica particles were contained within macrophages which were aggregated into foci around terminal and respiratory bronchioles. Small numbers of lymphocytes and fibroblasts surrounded these foci and were also intermingled within the macrophages (Figs. 2 and 3 ), while reticulin fibres were woven through and around the lesion. These general features of the dust lesions were to some extent influenced by the distribution of dust within the lung. Where dust deposition was very heavy the structure of the lung segments was completely obliterated by the presence of the lesions produced. In these areas the basic lesions consisted as before of a group of macrophages with a few fibroblasts and lymphocytes, but they were contiguous and their individuality was only distinguishable by virtue of the peripheral zone of fibroblasts and lymphocytes (Fig. 3). These confluent lesions were maximal 12 weeks after injection; with the passage of time dust was gradually eliminated from them, with some contraction of the lesion resulting in varying degrees of deformity of the lung. The individual lesions also decreased in size and number with time.

The size and number of the lesions was a function of the quantity of dust present in the lungs. For a given dust the lungs with the larger amounts of dust had the larger lesions and with the progressive elimination of the silica from the lungs there was a corresponding decrease in the size of the lesions and, towards the end of the experiment, in their number. The maximal size of the lesions was seen in the first groups of animals examined, 12 weeks after injection. In these sections the reticulin fibres were also most numerous and the amount tended to decrease as the lesions decreased in size during the course of the experiment.

There was little evidence that the lymphatic system was involved in the process of dust elimination. Within the lung itself dust was not often seen in lymphoid tissue. In those sections where paratracheal lymph nodes were present none or only small quantities of dust were seen. The small quantity which could be detected was contained within macrophages lying in sinusoids, and elicited virtually no reaction (Fig. 5). These observations do not preclude the possibility that significant quantities of dust were eliminated through the lymphatics.

The type of dust used affected the nature of the lesion, in the main by virtue of the different rates of excretion of the three samples; inspection of the micro-incinerated sections confirmed the analytical evidence that sample B was the most quickly eliminated from the lung and sample A2 the slowest. There appeared to be slight differences between the dusts in addition to this; sample A2 tended to have slightly 


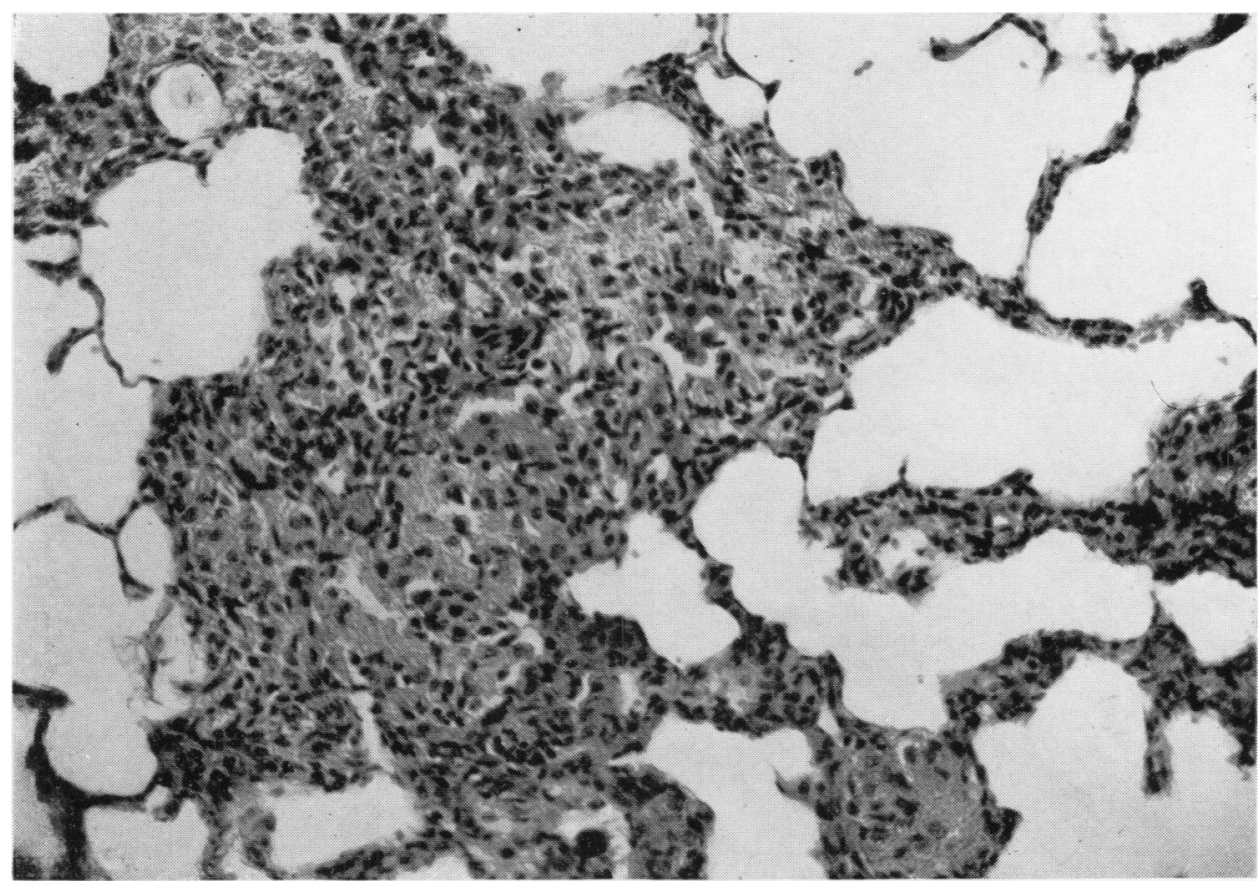

Fig. 2.-Rat lung 12 weeks after an intratracheal injection of $25 \mathrm{mg}$. of amorphous silica (sample B): an isolated lesion composed principally of macrophages. (H. and E. $\times 188$.)

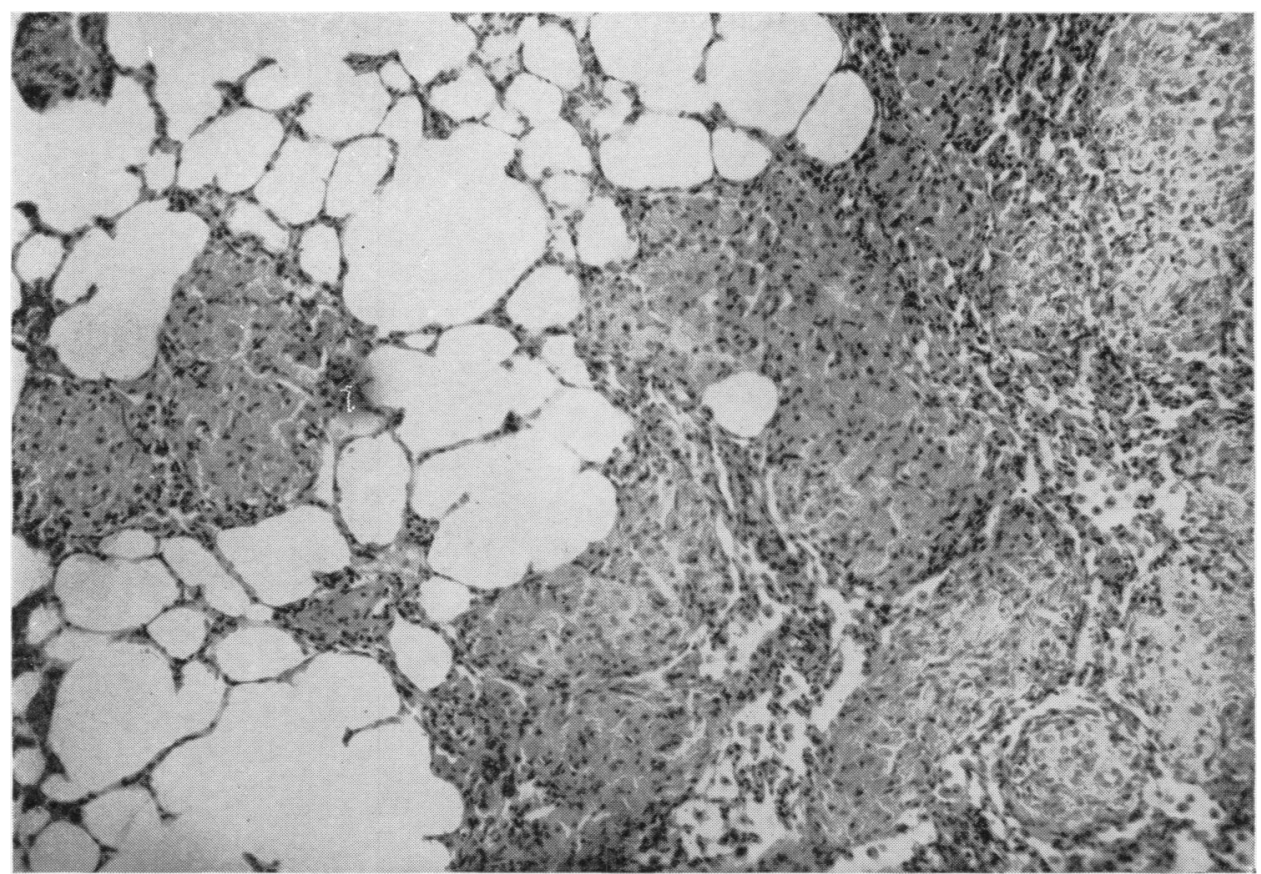

Fig. 3.-Rat lung 12 weeks after an intratracheal injection of $25 \mathrm{mg}$. of amorphous silica (sample A1): an isolated lesion at the left and confluent lesions to the right. (H. and E. $\times 100$.) 


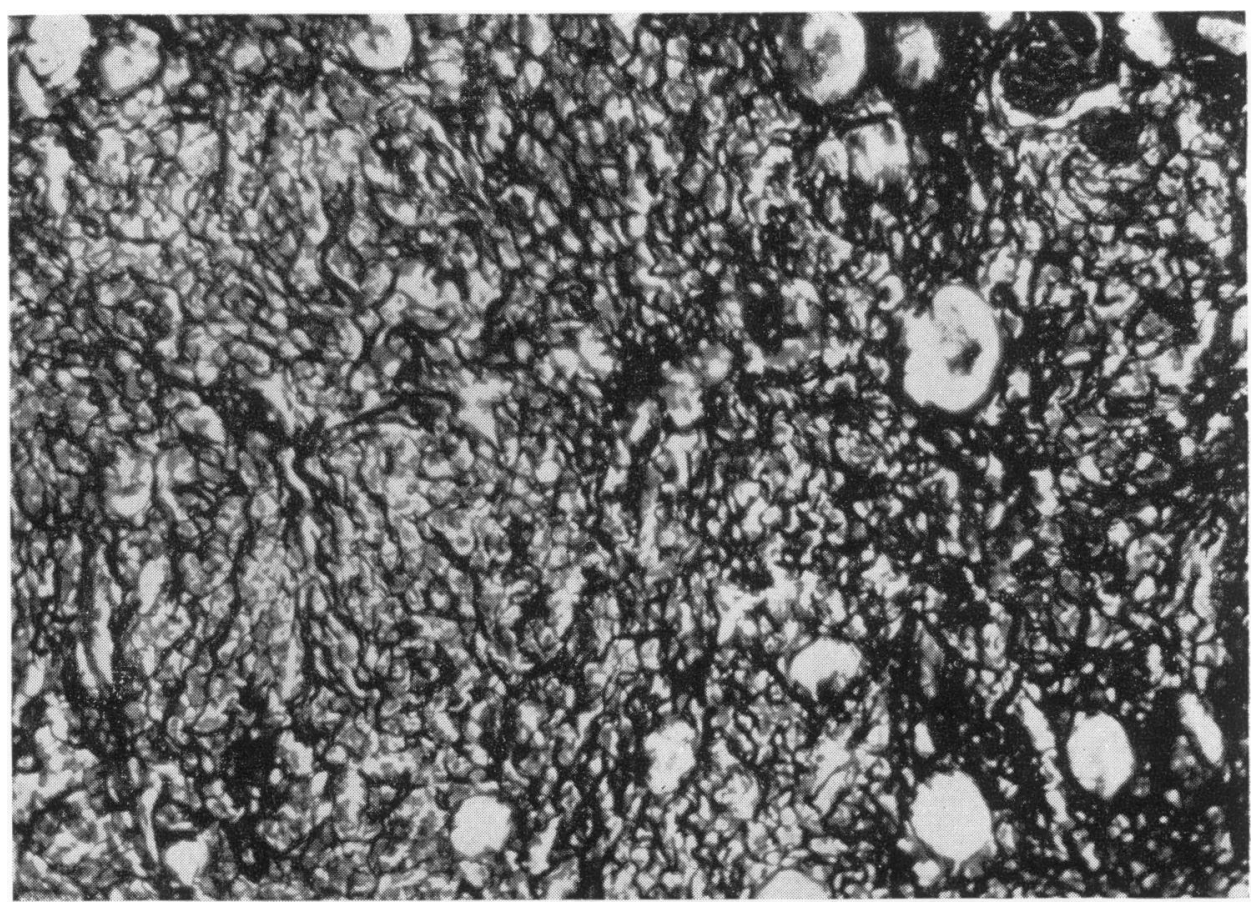

FIG. 4.-Rat lung 52 weeks after an intratracheal injection of $25 \mathrm{mg}$. of amorphous silica (sample A2): a portion of a confluent lesion showing loss of lung architecture and proliferation of reticulin fibres, with some collagen fibres. (Silver reticulin, neutral red $\times 150$.)

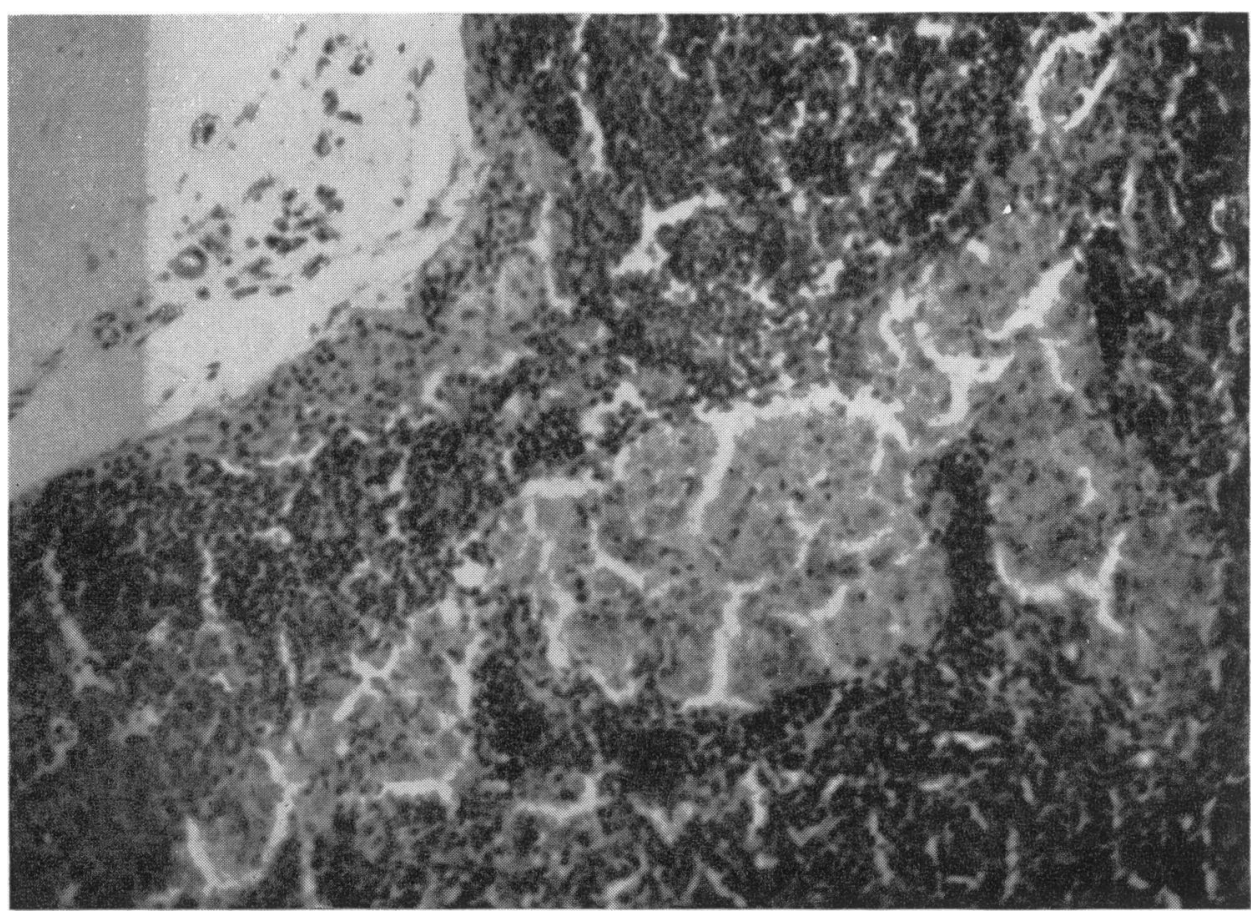

Fig. 5,-Rat mediastinal lymph node (the same animal as Fig. 4), 52 weeks after an intratracheal injection of 25 mg. of amorphous silica (sample A2): sinusoidal collections of macrophages with no associated inflammatory response or fibroblastic proliferation. (H. and E. $\times 200$.) 
larger lesions than the others for the same amount of dust, and also to induce a greater amount of fibroblastic proliferation which had the appearance of being more mature. As the lesions from this dust became smaller with time there was some condensation of the reticulin fibres giving rise to a rather more dense distribution at the periphery. In the first batch of animals examined, these lesions showed grade 1 , or in one animal grade 2 , fibrosis by Belt and King's (1945) classification, and at the termination of the experiment the lesions were graded as 1 minimal to 2 (Fig. 4).

The rats injected with sample A1 showed a slow and steady regression of the isolated lesions with an accompanying reduction of the reticulin fibres and no evidence of their maturation. The first batch examined showed lesions with grade 1 maximal to 1 fibrosis and at the end of the experiments the grades were 1 to $1 \mathrm{minimal}$; at this point sections from five animals showed no isolated lesions, while in others they were few and small. In areas of heavy dust deposition a rather milder effect was elicited than that from sample $A 2$, and regression went further over the period of observation. The lesions from sample B were initially similar to those from samples A1 (Figs. 2 and 3), but their rate of regression was more rapid and the final sections showed either a complete resolution or small scattered dust foci with few reticulin fibres around or within the lesion (fibrosis grade 1 to 1 minimal). There also remained a few areas of confluent lesions which were small and irregular and showed a rather light reticulin network and a little retraction.

In general the effect of the dust on lung function appeared to be small. There was evidence of mild emphysema in a few lungs but apart from a few large abscesses and foci of bronchiectasis there was little evidence of infection. Pneumonia and bronchopneumonia were infrequent. It does not seem likely that the presence of dust in the lungs greatly influenced the incidence or course of these infections, an opinion that tended to be confirmed by examination of 10 normal adult male and female rat lungs. In these animals microscopic and macroscopic inflammatory lesions were present with a similar overall frequency as in the lungs of the experimental animals.

\section{Conclusions}

The presence of particles of respirable size, to the extent of between one-quarter and one-third by weight, in dust clouds generated from the three samples of precipitated silica is evidence that the extent of aggregation is not sufficiently great to cause the dust to be entirely retained in the upper respiratory passages when inhaled and so preclude any cellular reaction in the lungs.
When precipitated silica is injected into rats' lungs a significant amount can still be detected by chemical analysis after a period of 12 months. The rate of elimination is, however, much faster than that observed with quartz and other fibrogenic dusts. Initially some of the silica leaving the lung appeared in the liver and kidneys, but with samples A1 and B no significant amount of silica could be detected in these organs six months after injection. Sample A2 was more persistent and was found in the liver and kidneys 12 months after injection. There is no evidence to indicate the route by which silica is eliminated from the lungs, and whether it is transported in the body as particles or in solution.

The lesions produced by the intratracheal injection of precipitated silica show little resemblance to those arising from quartz and were more akin to the effect of non-fibrogenic dusts. The most marked effect on the lungs was produced by sample A2 where there was a tendency for the lesions to coalesce with a loss of well-defined boundaries, but this in no way resembled the progressive reaction to quartz which produces an expanding lesion with maturation of fibres. Another notable difference resided in the evident regression of lesions during the course of the experiment, corresponding to the disappearance of silica from the lungs.

The severity of the lesions from precipitated silica was to some extent affected by the nature of the dust. Sample $A 2$ produced the largest and most persistent lesions and also a slightly greater deposition of fibres. It seems unlikely that any chemical difference existed between samples A1 and A2, which were initially made by identical processes, and it seems more probable that the greater activity of sample A2 can be attributed to those surface properties which resulted in its greater tendency to aggregate. This tendency could be observed both from the small proportion of fine particles in a dust cloud from this sample, and in the greater difficulty which was encountered in preparing an aqueous dispersion from it.

The single intratracheal dose technique is regarded as an efficient means of detecting the fibrogenic properties of a dust, and the absence of such a cellular reaction when precipitated silica is tested in this manner suggests that silicosis is unlikely to be encountered when materials of this type are used in industry. This does not imply that they are completely innocuous and precautions common to all other dusty materials should be taken to keep atmospheric contamination to a minimum. Where this is impossible, it is desirable that approved respiratory protection should be worn. Workmen exposed to these dusts should be subjected to periodic medical supervision, and should not be allowed to continue 
in their employment if there are signs of chronic respiratory disease.

Technical assistance in this investigation was provided by Mr. R. T. Ashmole and Mr. P. Salt.

\section{REFERENCES}

Belt, T. H., and King, E. J. (1945). Spec. Rep. Ser. med. Res. Coun. (Lond.), No. 250. H.M.S.O., London.

Dautrebande, L., Beckmann, H., and Walkenhorst, W. (1957). Arch. industr. Hith, 16, 179.
Davies, C. N. (1952). Brit. J. industr. Med., 9, 120.

Kettle, E. H., and Hilton, R. (1932). Lancet, 1, 1190. King, E. J., Stacy, B. D., Holt, P. F., Yates, D. M., and Pickles, D.

Klosterkötter, W., and Jötten, K. W. (1953). Arch. Hyg. (Berl.), 137,625 .

Pechukas, A., and Gage, F. W. (1946). Industr. Engng Chem. (Anal. ed.), 18, 370 .

Policard, A., and Collet, A. (1957). Arch. Mal. prof., 18, 50.

Schepers, G. W. H., Delahant, A. B., Bailey, D. A., Gockeler, E. L., and Gay, W. C. (1957a). Arch. industr. Hlth, 16, 499. Durkan, T. M., Delahant, A.

A. J. (1957b). Ibid, 16, 125.
Schrenk, H. H. (1939). U.S. Bureau Mines I.C. 7086.

Swensson, A., Glomme, J., and Bloom, G. (1956). A.M.A. Arch. industr. Hlth, 14, 482 .

Wright, B. M. (1954). Brit. J. industr. Med., 11, 284.

\section{THE JULY (1961) ISSUE}

The July (1961) issue contains the following papers:-

The Effect of Film Quality on Reading Radiographs of Simple Pneumoconiosis in a trial of $X$-ray sets. By F. D. K. Liddell.

A Survey of the Methods Developed in the National Coal Board's Pneumoconiosis Field Research for Correlating Environmental Exposure with Medical Condition. By J. W. J. Fay and J. R. Ashford.

Sickness Absence of Women Bus Conductors in London Transport (1953-1957). By C. J. Cornwall and P. A. B. Raffle.

Olfaction Tests. By I. Dingwall Fordyce.

Anosmia in Alkaline Battery Workers. By R. G. Adams and Norman Crabtree.

The Kidney in Lead Poisoning. By Zdenko Radoševič, Marko Šarič, Tihomil Beritič, and Jelica Kneževič.

Trithion Poisoning. By C. E. D. Hearn.

A Study of 104 Cases of Migraine. By A. J. Childs and M. T. Sweetnam.

\section{Book Reviews}

A number of copies are still available and may be obtained from the Publishing Manager, British Medical Association, Tavistock Square, W.C.1, price 17s. $6 d$. 